\title{
Sincretismos e os desafios da atualidade
}

Maria Cristina Castilho Costa

Professora livre-docente do Departamento de Comunicações e Artes

da Escola de Comunicações e Artes da Universidade de São Paulo.

Editora da revista Comunicação Ẽ Educação.

E-mail: criscast@usp.br

Houve um tempo em que aquilo que se entendia por cultura confundia-se com os aspectos materiais, típicos do estilo de vida de determinado grupo em certa época e lugar. Desse ponto de vista, a cultura poderia ser compreendida como ferramentas, roupas, comida, brinquedos, instrumentos musicais ou arquitetura própria desse grupo. Esses objetos constituíam o acervo visível e palpável que distinguia etnias, regiões, grupos etários, gêneros e classes sociais. O senso comum se habituou, assim, a pensar a cultura como o coletivo desses signos aparentes com os quais se identificava uma sociedade.

O desenvolvimento dos meios de comunicação e, conseqüentemente, das ciências da comunicação, levou os estudiosos a optar por um conceito mais imaterial e abstrato de cultura que incluía as linguagens utilizadas pelo grupo, o conjunto de seus símbolos e significados correspondentes. Essa tendência culminou com teorias como a do antropólogo Clifford Geertz, que afirma: "O conceito de cultura que eu defendo [...] é essencialmente semiótico. Acreditando como Max Weber que o homem é um animal amarrado a teias de significados que ele mesmo teceu, assumo a cultura como sendo essas teias e a sua análise"1.

Além do desenvolvimento do campo da comunicação, outras grandes transformações ocorreram na sociedade, marcando o mundo no século XX e abalando crenças e princípios que definiram a Modernidade. Uma dessas transformações foi o aceleramento da industrialização e de sua expansão pelo mundo, provocando a massificação da produção e do consumo e, conseqüentemente, dos hábitos cotidianos. Passamos a usar o mesmo tipo de roupa, a comer a mesma espécie de comida, a dançar a mesma música, e assim por diante. Essa homogeneização foi derrubando as fronteiras entre as culturas e suas especificidades, aproximando vertiginosamente populações que antes nos pareciam tão díspares. Ficou cada vez mais difícil identificar aspectos concretos, materiais e palpáveis capazes de distinguir diferentes grupos sociais.

Em conseqüência disso, pesquisadores como Edgar Morin consideram essa tendência homogeneizante uma característica de nossa época e de nossa sociedade, "uma tendência cosmopolita, que tende a enfraquecer as diferenças culturais nacionais em prol de uma cultura das grandes áreas transacionais"

1. GEERTZ, Clifford. A interpretação das culturas. Rio de Janeiro: Livros Técnicos e Científicos Ed., 1989. p. 15.

2. MORIN, Edgar. Cultura de massas no século $X X$ : o espírito do tempo 1 - neurose. Rio de Janeiro: Forense Universitária, 1984. p. 43. Grifo do autor. 
3. CANCLINI, Néstor García. Consumidores e cidadãos. Rio de Janeiro: UFRJ, 1995. p. 115

4. HOBSBAWM, Eric. Era dos extremos: o breve século XX (1914-1991) São Paulo: Cia. das Letras, 1995.
Porém, essa indústria massificada não produz apenas objetos que substituem a materialidade original dos grupos - a rede pela cama, a cerâmica pelo plástico -, mas também cada vez mais produtos imateriais e simbólicos, como imagens, sons, informações, discursos. Essa é outra grande transformação que marca o século XX: o desenvolvimento da indústria cultural em nível global, submetendo as diferentes culturas a um processo intenso de integração e homogeneização.

Esse processo foi uma das conseqüências da revolução tecnológica inventora de novos equipamentos para a produção de textos, imagens e sons, os chamados meios de comunicação, cada vez mais integradores e homogeneizadores. Trata-se de mais uma grande transformação que modificou profundamente o século XX: o desenvolvimento de uma cultura tecnológica.

Assim o século passado forjou as características da cultura contemporânea: globalizada, imaterial e tecnológica. Ou, como diria Néstor García Canclini, midiática. Segundo esse autor: "As indústrias culturais são hoje o principal recurso para se fomentar o conhecimento recíproco e a coesão entre os múltiplos organismos e grupos em que se enfrentam as grandes cidades".

Dessa forma, a educação como principal mecanismo social de elaboração e transmissão da cultura, nesse breve século $X X$, como o chamou o historiador Eric Hobsbawm, no livro a Era dos Extremos ${ }^{4}$, teve de se dirigir por novos parâmetros pedagógicos e fazer uso de novas linguagens pelas quais se difunde a cultura do nosso tempo. As relações entre cultura, meios de comunicação e educação são a tônica deste número de nossa revista.

\section{SINCRETISMOS}

Essa homogeneização da cultura promovida pelo desenvolvimento dos meios de comunicação, pela indústria cultural e por nosso cosmopolitismo não ocorreu por mera destruição das barreiras, das fronteiras e dos limites que antes separavam os grupos, as diferentes sociedades e seus estratos. Ela se verifica por processos de trocas e de ajustes que podemos chamar de plurais, híbridos ou sincréticos. Assim, as práticas educativas da contemporaneidade primam por essa combinação ou aproximação do que antes era diferente e estranho, pela capacidade de troca de conteúdos e de objetivos. Disso trata parte dos textos que ora apresento ao leitor.

Comecemos por Roberto Sobreira Pereira Filho e Edson Pereira da Silva, que estabelecem o diálogo entre educação e cultura contemporânea com um instigante artigo, no qual relacionam o videoclipe do grupo de rock Pearl Jam, Do the Evolution, com a lei da evolução das espécies proposta pela biologia. É mostrado que esse conteúdo, além de permitir o debate com os alunos a respeito da evolução e do progresso, possibilita uma visão crítica a respeito de tais conceitos. Trata-se de um sincretismo que enlaça pensamento científico e vida cotidiana, imagem e palavra, aprendizado e entretenimento. 
Sincretismo também está presente no artigo de três autores, Marcos A. Coelho, Ranylson Sá Barreto Neto e Maria de F. Marcelos, que procuram mostrar, através do relato de uma experiência escolar realizada no Centro Universitário Newton Paiva, a importância das metáforas no aprendizado das ciências contábeis. Integram-se nessa experiência ciências exatas e literatura, matemática e pedagogia, arte e ciência. Além disso, estabelecem-se relações e se ultrapassam fronteiras entre ficção e realidade, tomando-se ambas como formas válidas e distintas de se conhecer o mundo. E por falar em ficção...

\section{FICÇÕES}

Ficção e realidade são temas recorrentes quer para quem estuda a cultura na atualidade, quer para quem analisa os meios de comunicação de massa. Um mundo repleto de tecnologias que produzem imagens e reproduzem o espaço que nos cerca, alteram nossas percepções e interferem no conhecimento que adquirimos, armazenamos e transmitimos.

Luiz Antonio de Paula aborda em seu artigo o mundo da telenovela e a sinergia que existe entre os diferentes meios de comunicação na promoção dessa forma tão popular de narratividade ficcional. O autor mostra como as sinopses publicadas nos jornais modificam as expectativas dos telespectadores em relação àquilo que está por acontecer. Ele também resgata o poder do narrador na condução do público e reflete sobre sua importância na cultura urbana atual.

O Show de Truman é cinema e é ficção; porém, esse filme de Peter Weir, avaliado na crítica de Vander Casaqui, retrata a sensação que temos diante de um mundo cada vez mais controlado e editado pelos meios de comunicação. Trata-se da história de Truman Burbank, que, após trinta anos, descobre que sua vida nada mais é do que parte de um roteiro de televisão. A sensação que tinha de estar sendo vigiado acaba por revelar-lhe a ficcionalidade de sua própria existência. É um bom gancho para estudar autores importantes como Mikhail Bakhtin e Michel de Certeau.

Convergindo para essas preocupações, na seção Videografia sugere-se o filme Muito Além do Jardim, dirigido por Hal Ashby, para apresentação em sala de aula. A abordagem que se propõe dessa obra baseia-se nos textos de autores importantes como Giovanni Sartori e Edmond Couchot.

\section{POLÍTICAS PÚBLICAS}

Mas, se a cultura na atualidade precisa ser vista sob o ponto de vista das mensagens que circulam pela mídia e das interpretações de mundo que elas ensejam, essa perspectiva deve estar na escola, nos demais espaços educativos, assim como nas formas de intervenção social e nas políticas públicas, especialmente aquelas voltadas para a educação. 
Os Centros Educacionais Unificados - CEUs são a mais recente proposta de educação pública integral, buscando promover a educação formal de jovens e crianças, bem como garantir a formação complementar e continuada, o desenvolvimento de atividades esportivas, o lazer e a sociabilidade. Implantados em locais estratégicos, transformaram-se em grandes pólos educacionais e de convivência, sob a direção da Prefeitura Municipal de São Paulo. Seu pleno êxito, entretanto, depende de formas e canais adequados de comunicação com a comunidade. Pensar sobre isso e propor um melhor aproveitamento da comunicação no aperfeiçoamento da relação entre gestores, usuários e comunidade, foi a preocupação da Gestora de Comunicação Cristiane Hyppolito, que faz um relato de seu trabalho neste número da revista Comunicação Ė Educação.

É também pensando no público, entendido como um conjunto de consumidores de mensagens midiáticas, ou como instância de cidadania e partilhamento da vida coletiva, que a polêmica envolvendo educação e interesses empresariais faz sentido. Desde Marconi e as primeiras experiências com o rádio, a vocação educativa desse veículo esteve evidente. Mas como compatibilizar os objetivos educativos com os interesses comerciais? Esse é o assunto de que trata Lígia Beatriz Carvalho de Almeida, em Intencionalidade educativa em freqüência modulada: um desafio radiofônico.

Jorge Huergo, diretor do Centro de Comunicação e Educação da Universidade Nacional de La Plata, é nosso entrevistado deste número. E, de forma entusiasmada, sintetiza muito do que aqui já se falou, ao relatar suas experiências com aborígines, com jovens latino-americanos e com outros grupos sociais, no uso dos meios de comunicação de massa para estabelecer relações e conhecimento recíproco. Ele mostra como é possível promover o trânsito entre culturas, realizar práticas identitárias e de afirmação social através dos recursos midiáticos conjugados a propostas pedagógicas consistentes. Conhecedor de diversas experiências de comunicação e educação na América Latina, Huergo reconhece o protagonismo brasileiro na área.

Convergindo para esse enfoque na América Latina e em nossas similaridades e sincretismos, a seção Serviços apresenta um dos monumentos mais significativos da cidade de São Paulo: o Memorial da América Latina, apontado em recente pesquisa como um dos edifícios mais importantes projetados pelo arquiteto Oscar Niemeyer. Prestigiar esse monumento e aquilo que ele oferece ao público paulista, assim como a todos que visitam o Estado, foi nossa intenção.

\section{LINGUAGEM VERBAL E LITERATURA}

Sem nos esquecermos de que a linguagem verbal foi uma das primeiras tecnologias de comunicação e levando em consideração sua importância crescente até mesmo numa sociedade que valoriza muito a imagem, três textos deste número dedicam-se a seu estudo. Em primeiro lugar, há o artigo internacional de autoria de Dominique Morizot, que aborda a capacidade da linguagem verbal em revelar competências e performances dos falantes. Segundo a autora, 
Sincretismos e os desafios da atualidade - Maria Cristina Castilho Costa

tal propriedade exigiria que a escola tratasse a verbalização de um ponto de vista menos formal e mais abrangente, destacando-se a função identitária e estética da língua.

Na seção Poesia, Adílson Odair Citelli, como em números anteriores, busca descobrir e entender os mecanismos de passagem entre as diferentes discursividades que circundam a arte e a literatura. Analisando poesias de Solano Trindade, Ascenso Ferreira e Manuel Bandeira, Citelli estuda os arranjos fônicos e fonéticos que, ajustados à seqüência dos versos, extraem inspiração e ritmo do tema trem de ferro.

É também no terreno da expressão verbal que se distingue a depoente deste número da revista. Déborah Pádua Mello Neves é autora de livros didáticos que testemunham a expansão da educação e da indústria editorial no Brasil, marcada por grandes transformações que ela acompanhou e registrou em sua obra.

\section{FINALIZANDO}

Encerra-se o número, como sempre, com a valiosa contribuição de Ruth Ribas Itacarambi, que propõe atividades pedagógicas baseadas no conteúdo que preparamos para nossos leitores. Colocando-as em prática, o educador estará engrossando as fileiras daqueles que vêem na comunicação o melhor caminho a trilhar rumo à atualização da educação e ao enfrentamento dos inúmeros desafios da atualidade.

Resumo: O desenvolvimento dos meios de comunicação e, conseqüentemente, das ciências da comunicação levou os estudiosos a optar por um conceito mais imaterial e abstrato de cultura. Outras grandes transformações ocorreram na sociedade, marcando o mundo no século XX e abalando crenças e princípios que marcaram a Modernidade. $O$ desenvolvimento da indústria cultural, em nível global, submetendo as diferentes culturas a um processo intenso de integração e homogeneização, intensificou o desenvolvimento de uma cultura tecnológica. A educação, principal mecanismo social de elaboração e transmissão da cultura, teve que se dirigir por novos parâmetros pedagógicos e fazer uso de novas linguagens para difundir a cultura do nosso tempo. As relações entre cultura, meios de comunicação e educação são a tônica deste número da revista.

Palavras-chave: comunicação, cultura, indústria cultural, novas tecnologias, educação.
Abstract: Media and Communication Science development have taken scholars to opt for a more immaterial and abstract concept of culture. Other big changes have occurred in society, marking the world of the 20th century and shaking believes and principles of the Modernity. Cultural industry change, at global level, has submitted different cultures to an intense process of integration and homogenization intensifying the development of a technological culture. Education, main social mechanism of culture elaboration and transmission, was forced to follow new pedagogic parameters and make use of new languages to diffuse the culture of our time. Relationships among culture, media and education are this issue's keynote.

Keywords: communication, culture, cultural industry, new technologies, education. 


\section{वृค

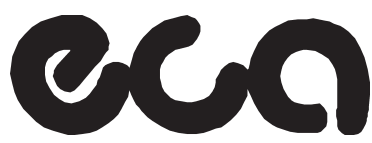

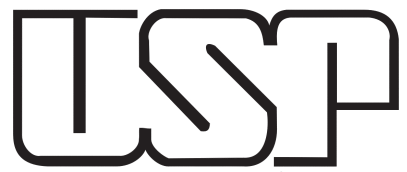

\section{ESPECIALIZAÇÃO LATO SENSU Gestão da Comunicação}

gestor da comunicação planeja e executa projetos de comunicação em empresas privadas, instituições públicas ou movimentos comunitários, nas áreas educacional, empresarial ou artístico-cultural.

- Capacitação do aluno para elaborar, implantar, avaliar e reestruturar projetos de comunicação/cultura.

- Integração teórico-prática da área de comunicação com o mercado de trabalho.

- Formação humanística e profissional sólidas, baseadas na inter-relação comunicação/cultura/artes.

- Qualificação do profissional, preparando-o para compreender o mercado emergente, em constante transformação, e agir sobre ele.
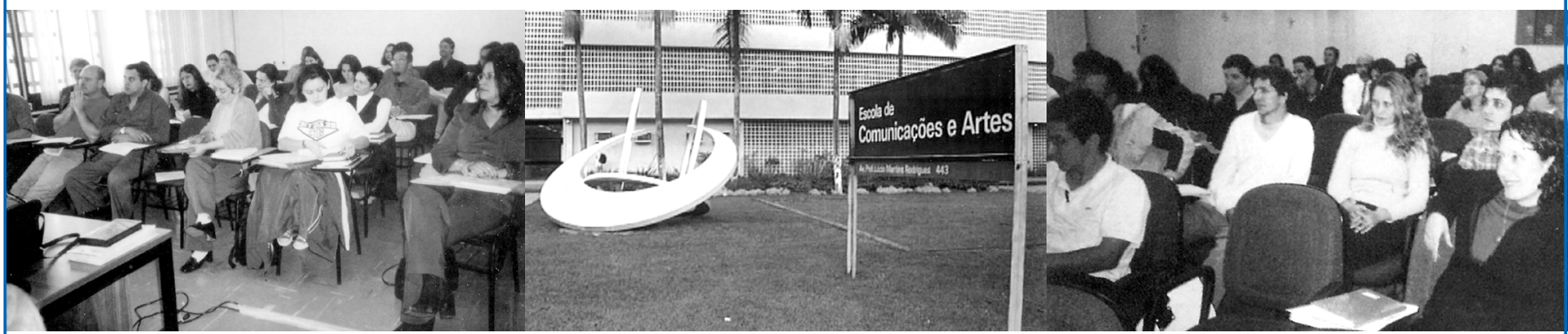

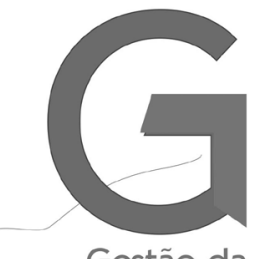

Gestão da Comunicação Especializaçäo lato sensu CCA - ECA - USP
Duração: três semestres

Pré-requisito: formação superior (qualquer área)

Seleção: prova escrita, entrevista e plano de estudo

Ingresso semestral: 1ำ semestre: turma com aulas às sextas-feiras e aos sábados 20 semestre: turma com aulas de segunda a quarta-feira

Informações: ECA/USP: 3091-4063/4341/4326 - e-mail: gestcom@edu.usp.br www.eca.usp.br/gestcom 